\title{
Contributions to a Regenerated Social Science: A Review
}

\author{
LARRY J. FISK*
}

\begin{abstract}
By 1965 , behavioral social science had become a widely accepted approach to the scientific study of man and his politics. Any uncertainty as to what constituted a proper social science seemed to be raised most deeply by writers acquainted with the nature of physical science which most social science methodology seemed desparately to emulate.

Recent comments by Nobel physicist Hideki Yukawa seem to indicate that little has changed in the physicist's scientific method in the last ten years and it would appear to be time to review those theories which prompted some radical reconsideration of the nature of both natural and social science over the last decade.

The ideas which seem to lead to such a reconsideration include Werner Heisenberg's principle of uncertainty - that the observer's attempt to pin-point one phenomenon in nature disrupts or interferes with closely related phenomena; and Niels Bohr's principle of complimentarity where two seemingly different or contradictory theories when taken together offer a more complete understanding of a given phenomenon in the physical world. Michael Polanyi's notions of "tacit knowledge" and "indwelling" indicate that "we know more than we can tell" and that our view of isolated and detailed aspects of reality are rooted in a "prior knowledge" or even "involvement" in a larger whole. The capability of seeing or sharing in such larger wholes has been considered by humanistic psychologist Abraham Maslow as a measure of the scientist's maturity. A social scientist is open to more when he is a healthy person.

Empathy, participation and man's purposefulness are the three human characteristics considered in this paper all of which seem to appear as the crux of a science of man by which all science must reinterpret its own methodology. To so interpret such characteristics rather than tailoring them to fit existing physical and behavioral scientific method and theory is to put certain ethical and political responsibilities of the social scientist at the very center of the nature, method and theory of our understanding of man and the science of man.
\end{abstract}

The theories of Heisenberg, Bohr, Polanyi and Maslow support such a radical reinterpretation and the conclusion of the paper is that such a reinterpretation does not so much redefine social science in the light of natural science, but puts a reconsideration of the 
nature of man and science at center stage, so that a total regeneration of all science may be possible.

The June 1974 newsletter of the Harvard Program on Public Conceptions of Science notes that "much of the public interest science literature appears to make the tacit assumption that expert scientists can and should continue to engage in traditional 'neutral' science and not be accountable to the larger society, even while assuming new, highly visible, and politically sensitive roles." Perhaps not too much has changed in our understanding of the nature of science in the last decade if the newsletter's analysis is correct. In spite of the seeming breakthrough in our reconsideration of what "real science" was all about, Hideki Yukawa, physicist and first Oriental to receive a Nobel prize, has very recently complained of the same shortcoming of science opened up by Werner Heisenberg ten to twenty years earlier.

The "trend to abstraction", says Yukawa:

has gone to extremes during the last twenty years. ... Abstraction cannot work by itself, but has to be accompanied by intuition or imagination... . The power to predict is almost lost and theoretical physics has largely been reduced to a general and abstract way of describing what is already known empirically. . . Another rejuvenation of fundamental physics may be expected if greater regard is given to intuition or bold imagination as a supplement to the inevitable trend to abstraction. ${ }^{1}$

Perhaps it is time to review the thinking of those scientists who, like Yukawa, have been forced to stare in the face of their limitations, and to once again consider the implications that their rethinking of science have for the social scientist and his study of man.

What these natural scientists, and philosophers of science like Michael Polanyi, have done for social science is to counter the attack of those who said that there were certain dimensions involved in understanding man and his social environment which made the application of the scientific method (as known in the physical sciences) totally inappropriate or inadequate. The arguments to follow will examine a few such alleged stumbling blocks: empathy, participation and man's purposefulness.

We might begin by reconsidering a typical defence of contemporary social science as many of us received it in graduate school over the past decade. What we faced was a number of social scientists and philosophers of science like Quentin Gibson (The Logic of Social. Inquiry) who argued that man's purposeful behavior - his intentions and reasons - had been too long viewed as making any cause and effect analysis of social phenomena inappropriate. The reasons man behaves may be totally removed from the causes surrounding a particular event. It is, supposedly, the inability to abstract likenesses from human purposefulness and make generalizations or universal laws or explanations of such likenesses which would make the scientific study of man impossible. A man like Quentin Gibson views abstraction as a process of distinguishing features: a selection of likenesses or differences. Features are not to be confused as parts or chunks of the whole. Features are, rather, the almost endless possible relationships and dimensions to human behavior and social activity. By stressing both like and unlike features we are able to say that investigation into individual reasons (albeit very different ones at times) many be a form of abstraction not un- 
like that performed in other scientific endeavors. Reasons throw light on purposes and ends - they serve as explanations. ${ }^{2}$

Similarly, it was argued that empathy need not be an extra-scientific dimension of understanding found in social studies but not in natural science. For empathy, according to Gibson, is simply a more efficient means of gathering evidence. The observer is simply in an advantageous position to gather evidence, for example, in the midst of some primitive tribe observing "the daily round of inconspicuous activities." 3 In short, by reducing empathy, purposeful behavior and involvement in social life to the predominant scientific world view of detached objectivity in physical life, the potential forces for a radical re-examination of the nature of all scientific inquiry could be snuffed out at birth.

It is within the context of such ready dismissals of the revolutionary significance of empathy and participation that the first of the important theories I wish to review is related. Werner Heisenberg's principle of indeterminacy or uncertainty destroys any distinction that would proffer participation in social but not in physical or natural phenomena, but in such a way as to produce a new and wider interpretation of science.

The principle of indeterminacy arose out of the discovery that it was impossible to measure both position and velocity of microphysical particles, and consequently the whole process of cause and effect determinacy broke down. Relatedly, neither position nor velocity of molecular particles could be observed without affecting one or the other. If a physicist wishes to observe position, he must be prepared to "control" velocity and vice versa. "Every process of observation produces a large disturbance," Heisenberg noted. ${ }^{4}$ And, in fact, pressing too hard for the understanding of one variable results in the loss of the other. Such findings eventually convinced Heisenberg that science ceased to speak for nature and "reality" itself but, rather, for man and his observation of reality. "Man increasingly confronts himself alone," said Heisenberg. The "buildingstones of matter," once "held to be the last objective reality," are no longer considered "in themselves" since "they defy all forms of objective location in space and time." Physics no longer paints a picture of nature but rather "a picture of our relationships with nature."s

Heisenberg's principle ends any clear distinction between participation in social science as against natural science. The ground of understanding is prepared so that empathy and participation can be seen to be the revolutionary dimension to all human learning.

The second important principle closely related to indeterminacy was physicist Niels Bohr's principle of complementarity. By being used alternatively, perhaps in different situations and under different conditions, both wave and particle or quantum theories of light could be used to explain the same or related phenomena. The complementarity of two seemingly opposing theories of light employed alternatively has become a breakthrough in human understanding in physics. The principle can be applied as well to social science as, for example, to our understanding of the natural causes and human reasons involved in the same event, or to the social functions and human purposes in the same society or institution. 6

The third major source of new thinking which has been applied to the questions at hand is Michael Polanyi's view of the tacit dimension to human knowledge. Polanyi argues that "we know more than we can tell." We can "recognize" a friend's face and yet be unable to describe the separate features of that face. A comprehension of the whole, therefore, is different from a knowledge of the sum of its parts, just as three gallons of water and three of alcohol do not add up to six gallons of fluid. ${ }^{7}$ Had we never seen a frog, no sum of the 
parts of one would offer an understanding of what a frog is. In fact, we recognize the parts of a frog, machine, perhaps even staff meetings, because of our prior knowledge of the whole complex of relationships.

Similarly, the creative process of "seeing a problem" is to see something that is hidden: "to have an intimation of the coherence of hitherto uncomprehended particulars." The formulation of a problem, therefore, and the acceptance as true of discoveries contingent upon its formulation involves a commitment of ourselves "to a belief in all these as yet undisclosed, perhaps, as yet unthinkable, consequences." 8 What is determined to be worthy of investigation by the scientist becomes a decision based on fundamental convictions about the nature of things.

It is at this point that humanistic psychologist Abraham Maslow's stress on the psychological health of the scientist gains significance. In much of his last writing before his death in 1970 Maslow argued that many researchers have either deficiency or defensive needs while others are moved by growth or coping mechanisms. The search for knowledge, Maslow claimed, can be merely an anxiety-allaying procedure concerned with need-reduction. ${ }^{9}$ But once personal problems are being resolved, "we can get truly interested in the world for its own sake." In short, psychological health produces a better knower.

A part of this psychological health is knowing one's self and honestly coming to grips with one's strengths and shortcomings. Such experiential knowledge which may contain elements of fearlessness, ego-transcendence, honesty, unselfishness and dedication precedes spectator knowledge and breeds one's effectiveness as an "instrument of knowledge."

Empathy, therefore, rests upon the experiential knowledge and psychological health Maslow spoke about - an honest, objective gathering of empirical evidence where, as Gibson states, one does not substitute the taste of strawberries for the pain of the pinprick. But the kind of prior emphasis on experiential knowledge is not the emphasis that Quentin Gibson, Robert Brown (Explanation in Social Science) and so many social scientists and philosophers of science have stressed. So if we are to arrive at a better position from which to question the predominant views of social science, we ought to tie Maslow's comments to one further concept coming from Polanyi - that of "indwelling."

Polanyi claims that tacit knowing implies an indwelling within the subject matter. One in a sense dwells in the whole of the matter being understood and so in some sense is embraced by the entire subject. We do not explain higher level developments in terms of lower. For example, the physics and chemistry of brickbuilding, the technique of bricklaying, the art of architecture and city planning cannot entertain the explanation of any higher level by a lower. But we do employ the lower level particulars within the context of our attention to higher level realities, problems, experiences, etc. "We know each level by interiorizing its particulars and mentally performing the integration which constitutes it." 10

Instead of observing [particulars] in themselves, we may be aware of them in their bearing on the comprehensive entity which they constitute. It brings home to use that it is not by looking at things, but by dwelling in them, that we understand their joint meaning. ${ }^{11}$

Indwelling, therefore, is something more than empathy; it underlies all observation. As a part of all observation "from the minimum of indwelling, exercised in a physical observation, we move without a break to the maximum of indwelling which is a total commitment."12 
It is interesting to consider the effect of undue attention given to particulars - for example, the paralysis which might set in if a concert pianist were to focus attention on the movement of his fingers. Polanyi admits that if attention to particulars is later interiorized it may increase knowledge, but he deems it more likely that "meticulous detailing may obscure beyond recall a subject like history, literature or philosophy."

Polanyi points to what he believes to be a fundamental fallacy - the "belief that, since particulars are more tangible, their knowledge offers a true conception of things."

The declared aim of modern science is to establish a strictly detached, objective knowledge. Any falling short of this ideal is accepted only as a temporary imperfection, which we must aim at eliminating. But suppose that tacit thought forms an indispensable part of all knowledge, then the ideal of eliminating all personal elements of knowledge would, in effect, aim at the destruction of all knowledge. The ideal of exact science would turn out to be fundamentally misleading and possibly a source of devastating fallacies. ${ }^{13}$

Rather than attempting to argue that empathy, sympathy, participation or involvement, purposeful behavior and imagination are really not all that different from the usual forms of scientific evidence-gathering in the physical realm, the concepts of tacit knowing and indwelling attempt to incorporate all of the above within themselves and make such means of gaining knowledge essential to all realms of science, social and natural. In other words, instead of trying to argue that there is really no difference between natural and social science and no stumbling blocks to the applications of the former to the latter, we should see in the creative ways of understanding man and his social millieu some indication of how all of reality is understood: ways which have previously gone without proper recognition. When Gibson, Brown, and others argue that empathy, for example, is essentially a classical form of evidencegathering, save for a better position, the result of such an argument is that we have an all too simple view of the whole dimension of human understanding. Scientific abstraction is to be understood, therefore, not just as a selection of features from the whole but as abstraction based on prior experience of the whole.

Empathy makes a difference not just because of an advantageous position for gathering evidence but because of a "caring" relationship - a qualitative or moral difference. In the way that Maslow talked about the mature and healthy knower (arising out of empathy and participation or involvement) we have what he called a "helpful" dimension to understanding. We are, most of us, aware of drug addicts or problem drinkers who say of certain persons that they "really know" the problem and only they can "really help." Most of those who "really know" have shared the problem and care for those who now face it. Maslow went on to argue that perhaps all knowledge is related to such a caring relationship if only to the extent that we can speak of a "love for" or "interest in" subjects and problems even by astronomers or chemists. ${ }^{14}$

The dimension of understanding to which we refer is also characterized by trust. Margaret Mead has said of her own field: "Anthropological research does not have subjects. We work with informants in an atmosphere of trust and mutual respect."15

The observer in Quentin Gibson's tribal society who observes the inconspicuous activities of the daily round, therefore, does so in large measure because he trusts and is trusted, he exhibits concern and sees the meanings and importance (a tacit dimension) and behaves 
ethically, consequently perceiving and understanding relationships that cannot otherwise be comprehended.

One short comment on detachment may also be in order. Heisenberg, we should recall, claimed that men see that reality which results out of their decisions as to what it is they wish to observe. Or we are constantly grasping and shaping reality, as theologian Paul Tillich preferred to say. In fact, "we transform reality according to the way we see it, and we see reality according to the way we transform it," Tillich said. ${ }^{16}$

Our interest and emotion, therefore, become vehicles for perceiving knowledge. "Reason is like a light which by its own inner force can move nowhere. It must be carried in order to move."17 Interest and emotion become such carriers. The content (reason) is not, therefore, necessarily emotional; but nothing is moved, transmitted and received cognitively without emotion. Detachment, therefore, is a condition of a prior cognitive union. It is informative to note that Asiatics take the unifying, healing, transforming powers of knowledge as a matter of course. "Their problem - never completely solved - is the element of distance, not that of union," Tillich observed. He explained further by adding that there are "levels in man's bodily, psychic and mental constitution which can and must be grasped by [detachment]. But this is neither the way of knowing human nature nor is it the way of knowing any individual personality in past or present, including one's self." 18

This is not to say that some alternative method of understanding man is posited by Tillich, but rather, that our scientific study of man can involve considerably more than detached value-free analysis, and must involve more, if we are to properly understand ourselves and our social and political lives.

To re-evaluate the place and importance of detachment and objectification in the manner begun above ought to raise for us the question of verification and the validation of our understandings. As long as we remember that verification is rooted in experiential knowledge, there is probably not too great a problem here. Maslow offered us the case of the man who talked of having viewed an "unheard of" animal in the midst of a desert. Verification demands the right of other people to see that animal for themselves; hence, as Maslow pointed out, such a right is what verification is all about: i.e. an extension of "see for yourself." 19 The validation of many experiences (say, of "knowing" a political leader's meanings, reasons, intentions and values) may come to fruition only in "the life-process itself"; that is, over time "it fits."20 Verification may also take the form of the illumination of, let us say, political figures in past or present.

It is of the utmost importance to bear in mind that all processes of verification measure findings against "established truths" and that established truths and, in fact, all existing knowledge and means of proof, must be subject to yet larger truths. Otherwise, the profound skepticism which denies this view would destroy the very love of truth upon which the scientific community is built. Polanyi argued this point by stating:

The method of disbelieving every proposition which cannot be verified by definitely prescribed operations would destroy all natural science and it would destroy, in fact, belief in truth and in the love of truth itself which is the condition of free thought. The method leads to complete metaphysical nihilism and thus denies the basis for any universally significant manifestation of the human mind. ${ }^{21}$

Consequently, profound and critical reflection on what we know to be science or scienti- 
fic procedure; on what one does, or how one thinks and functions, as a scientist; ought to be a constant endeavor. Such knowledge ought always to be reappraising its roots and enlarging its understanding of itself - a philosophical task of great significance. This reappraisal is precisely what Heisenberg, Bohr, Polanyi, and Maslow have set out to do. Their success as scientists combined with the revolutionary vitality to their thought about science ought to have been cause for careful soul-searching on the part of the rest of us, whatever our scientific discipline.

As we conclude, then, we are left with questions of direction and moral or ethical responsibility. The responsibilities which face us are (1) the philosophical task of reflecting on science and the nature of research and (2) the decisions that each of us must make as to what we want to know, why we want to know it and how we are to come to know it. Decisions on the "what," "why," "how" questions will determine the direction scientific endeavors take. Once again, then, we become responsible for those directions.

Perhaps the point which is more closely related to what I have attempted to review here, however, is that the principles of uncertainty and complementarity plus the notion of tacit knowledge remind us at every stage that we scientists (social or physical) are actors; that we cannot avoid our "indwelling" relationship to the world of nature, man, or politics we seek to understand. And we will by how we answer those questions of direction; we will by what we choose to study, and how and why we choose to study it - we will reshape our society and politics; we will refashion our world - for better or worse.

\section{Footnotes}

1. Hideki Yukawa, Creativity and Intuition: A Physicist Looks at East and West (New York: Kodansha International/USA Ltd., 1973) as cited in Lee C. Teng, "Hideki Yukawa: The Metaphysics of Physics," Bulletin of the Atomic Scientists, March, 1975, pp. 48-49.

2. Quentin Gibson, The Logic of Social Inquiry (London: Routledge and Kegan, 1960), pp. 7-9, 29-40.

3. Ibid., p. 51.

4. Werner Heisenberg, The Physicist's Conception of Nature (New York: Harcourt, Brace and Company, 1958), p. 15.

5. Ibid., p. 24.

6. For further examples see Bohr's essay, "Quantum Physics and Philosophy - Causality and Complementarity," in Niels Bohr, Essays 1958/1962 on Atomic Physics and Human Knowledge (New York: John Wiley and Sons, 1963).

7. Henry Margenau, Open Vistas: Philosophical Perspectives of Modern Science (New Haven: Yale University Press, 1961), p. 64.

8. Michael Polanyi, The Tacit Dimension (Garden City, N.Y.: Doubleday and Company, 1966), pp. 21-23.

9. Abraham H. Maslow, The Psychology of Science: A Reconnaissance (New York: Harper and Row, 1966). Maslow claimed that all the words associated with scientific investigation - "prediction, control, rigor, certainty, exactness, preciseness, neatness, orderliness, lawfulness, quantification, proof, explanation, validation, reliability, rationality, organization, etc., - are all capable of being pathologized when pushed to the extreme." Maslow surmised that the "merely cautious knower, avoiding everything that could produce anxiety (the wild, crazy, loose, uncontrolled, puzzling, guessing, fantastic, playful) is partially blind. The world that he is able to know is smaller than the world that the strong man can know." pp. 30-32.

10. Michael Polanyi, "Science and Man's Place in the Universe," in Harry Woolf, ed., Science as a Cultural Force (Baltimore: John Hopkins Press, 1964), pp. 70-71. 
11. Polanyi, Tacit Dimension, pp. 17-18.

12. Polanyi, "Science and Man's Place," pp. 70-71.

13. Polanyi, Tacit Dimension, pp. 19-20.

14. Maslow, Psychology of Science, pp. 108-09.

15. Margaret Mead, "Research with Human Beings: A Model Derived from Anthropological Field Practice," Daedalus XCVIII, (Spring, 1969), p. 361.

16. Paul Tillich, Systematic Theology, Vol. I (Chicago: University of Chicago Press, 1951), p. 76.

17 Hans J. Morgenthau, Scientific Man Versus Power Politics (Chicago: University of Chicago Press, 1946), p. 155.

18. Tillich, Systematic Theology, p. 98.

19. Maslow, Psychology of Science, p. 70.

20. Tillich, Systematic Theology, p. 102.

21. Michael Polanyi, Science, Faith and Society (London: Oxford University Press, 1946), p. 62. 